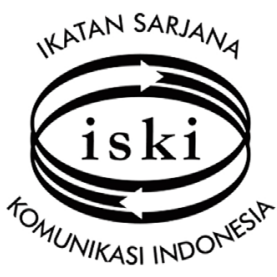

\title{
MENINGKATKAN KECERDASAN BANGSA MELALUI OPTIMALISASI PENERAPAN STANDAR KOMPETENSI WARTAWAN
}

\author{
Sri Herwindya Baskara Wijaya ${ }^{1}$, Firdastin Ruthnia Yudiningrum ${ }^{2}$ \\ ${ }^{1,2}$ Program Studi Ilmu Komunikasi Fakultas Ilmu Sosial dan Ilmu Politik \\ Universitas Sebelas Maret Surakarta \\ r_windya@yahoo.com,firda.ry@gmail.com
}

\begin{abstract}
Abstrak
Iklim demokratisasi pascareformasi tahun 1998 kian menabalkan pers Indonesia pada posisi dan peran yang penting. Dalam posisi ini, kedudukan dan peran wartawan sebagai ujung tombak pers menjadi sangat menentukan. Wartawan dituntut mampu menghasilkan produk-produk jurnalistik yang menjadi katarsis informasi bagi masyarakat luas. Untuk itu optimalisasi penerapan standar kompetensi wartawan tak terelakkan. Hal ini sangat urgen untuk memandu para wartawan Indonesia dalam bekerja secara profesional baik menyangkut kompetensi kesadaran, kompetensi pengetahuan maupun kompetensi keterampilan. Optimalisasi penerapan standar kompetensi wartawan di Indonesia dapat ditempuh melalui: (1) optimalisasi pelatihan/kursus/workshop/ studi banding, (2) optimalisasi monitoring dan evaluasi (Monev), (3) optimalisasi pemberian penghargaan, (4) optimalisasi penerapan sanksi secara obyektif, selektif, bertahap, adil, prosedural dan edukatif, (5) optimalisasi kesejahteraan wartawan, (6) optimalisasi advokasi wartawan, (7) optimalisasi uji kompetensi wartawan.
\end{abstract}

Kata Kunci: Standar Kompetensi Wartawan, Pers, Profesional, Kecerdasan Bangsa

\section{PENDAHULUAN}

Perkembangan demokrasi di Indonesia semenjak bergulirnya reformasi 1998 telah membawa dunia pers Indonesia ke dalam suatu babak baru: kebebasan. Jurnalis beroleh kekuatan yang sangat besar nyaris tanpa kendali (kecuali oleh modal). Situasi ini mengkhawatirkan sebagaimana terbaca dalam lontaran khalayak tentang "kebebasan pers yang kebablasan" (Syah, 2011).

Semua itu akarnya bersumber dari kualitas sumber daya manusia (SDM) termasuk para jurnalis yang memproduksi berita. Jika SDM jurnalis berkategori berkualitas tinggi, maka hasil karya jurnalistik mereka juga akan berkualitas baik. Sebaliknya jika SDM jurnalis berkualitas rendah maka karya jurnalistik mereka juga akan berkualitas rendah (Wijaya, 2015: 96). Profesi wartawan menuntut tanggung jawab yang memerlukan kesadaran tinggi dari pribadi-pribadi wartawan sendiri (Kusumaningrat dan Kusumaningrat, 2009: 1). Oleh karena itu, dalam melaksanakan tugasnya wartawan harus memiliki standar kompentensi yang memadai dan disepakati oleh masyarakat pers (Dewan Pers, 2010).

Terlebih lagi, bangsa kita dihadapkan dengan berbagai tantangan di berbagai bidang terutama masalah korupsi, supremasi hukum, kegaduhan politik dan aksi terorisme, atau meminjam istilah Syafi'iMaarif(2015), suasanamoralbangsa(Indonesia) yang masih ringkih, goyang dan bahkan rapuh sampai saat ini. Azyumardi Azra menyebut Indonesia sedang mengalami krisis sosial budaya yang meluas (Azra, 2007: 7). Makalah ini mencoba mengelaborasi lebih mendalam mengenai optimalisasi penerapan standar kompetensi wartawan di Indonesia untuk ikut dalam mencerdaskan kehidupan bangsa.

\section{KERANGKA TEORITIS}

Lasswell (1960) mencatat ada tiga fungsi media massa yaitu pengamatan lingkungan (surveillance), korelasi bagian-bagian dalam masyarakat untuk 
merespons lingkungan (correlation) dan penyampaian warisan sosial masyarakat dari satu generasi ke generasi selanjutnya (transmission of the social herritage). Selain ketiga fungsi ini, Wright (1959) menambahkan fungsi keempat yaitu hiburan (entertainment) (Severin dan Tankard, 2005).

Fungsi pengawasan yakni media massa memberikan informasi dan menyediakan berita. Fungsi korelasi yakni seleksi dan interpretasi informasi tentang lingkungan. Fungsi penyampaian warisan sosial merupakan fungsi dimana media menyampaikan informasi, nilai dan norma dari satu generasi ke generasi berikutnya atau dari anggota masyarakat ke kaum pendatang. Sementara fungsi hiburan dimaksudkan untuk memberi waktu istirahat dari masalah setiap hari dan mengisi waktu luang (Severin dan Tankard, 2005).

Dye dan Zegler mengidentifikasi fungsi politis media massa. Fungsi meliputi lima hal pokok: (a) fungsi pemberitaan, (b) fungsi interpretasi, (c) fungsi sosialisasi, (d) fungsi persuasi, dan (e) fungsi pengagendaan isu (Pawito, 2005: 93).

Dewan Pers (2005), mendefinisikan kompetensi wartawan sebagai kemampuan seorang wartawan melaksanakan kegiatan jurnalistik yang menunjukkan pengetahuan dan tanggung jawab sesuai tuntutan profesionalisme yang dipersyaratkan.

Standar kompetensi wartawan bertujuan untuk: (1) Meningkatkan kualitas dan profesionalitas wartawan, (2) Menjadi acuan sistem evaluasi kinerja wartawan oleh perusahaan pers, (3) Menegakkan kemerdekaan pers berdasarkan kepentingan publik, (4) Menjaga harkat dan martabat kewartawanan sebagai profesi khusus penghasil karya intelektual, (5) Menghindarkan penyalahgunaan profesi wartawan, (6) Menempatkan wartawan pada kedudukan strategis dalam industri pers.

Berdasarkan Peraturan Dewan Pers Nomor 1/ Peraturan-DP/II/2010 tentang Standar Kompetensi Wartawan, setidaknya kompetensi wartawan dibagi menjadi tiga kelompok, yakni: (1) Kesadaran (awarness) mencakup kesadaran tentang etika, hukum dan karir, (2) Pengetahuan (knowledge) mencakup pengetahuan umum dan pengetahuan khusus sesuai bidang kewartawanan yang bersangkutan, (3) Keterampilan (skills) mencakup keterampilan menulis, wawancara, riset, investigasi, menggunakan berbagai peralatan seperti komputer, scanner, faksimili dan sebagainya.

\section{METODE PENELITIAN}

Metode yang dipakai pada penelitian di makalah ini adalah observasi yakni mengamati fenomena penerapan standar kompetensi wartawan di Indonesia dewasa ini serta menggunakan dokumentasi berupa studi literatur berbagai referensi tekstual terseleksi atas obyek riset.

\section{HASIL PENELITIAN}

Untuk meningkatkan optimalisasi penerapan standar kompetensi wartawan di Indonesia setidaknya dapat ditempuh melalui beberapa hal:

\section{Optimalisasi Pelatihan/Kursus/Workshop/ Studi Banding}

Langkah ini berupa peningkatan keahlian wartawan melalui pendidikan kompetensi seperti melalui pelatihan/kursus/workshop/studi banding. Materi pelatihan materi kompetensi kesadaran (nilai-nilai etika/moralitas, regulasi/hukum pers dan karir), materi kompetensi pengetahuan (pengetahuan umum, pengetahuan khusus terkait bidang liputan dan materi khusus soal konsep/teori jurnalistik dan komunikasi; bahasa asing) dan materi kompetensi teknis (teknik menulis, wawancara, lobi, teknologi komputer/laptop, internet, faximily, scanner, gadget, email, chatting, media sosial dan lain-lain).

Pelatihan/kursus/workshop ini perlu dilakukan secara lebih rutin dan terprogram pada setiap level wartawan secara kuantitas maupun kualitas. Implementasinya baik teori maupun praktik dengan pemateri yang kompeten di bidangnya. Selain itu, bisa juga melalui pengiriman wartawan yang ditunjuk secara bergiliran untuk mengikuti pelatihan/studi banding tentang kompetensi kerja jurnalistik ke instansi dalam atau luar negeri.

\section{Optimalisasi Monitoring dan Evaluasi (Monev)}

Langkah ini berupa optimalisasi monitoring dan evaluasi atas kerja wartawan. Hal ini seyogyanya bisa dimulai dan dilakukan oleh setiap individu wartawan sehingga bisa lebih maksimal dan berhati-hati dalam bekerja. Optimalisasi Monev atas wartawan bisa juga oleh perusahaan pers yakni memantau dan mengevaluasi proses dan hasil kerja para wartawan sesuai dengan target dan standar operasional jurnalistik baik teknis maupun nonteknis. Monev harus dilaksanakan dengan tata aturan yang jelas dan 
memperhatikan kekondusifan suasana batin dan suasana kerja wartawan.

Optimalisasi Monev atas kompetensi wartawan juga perlu dilakukan lembaga-lembaga lain yang berkorelasi dengan tata kelola jurnalisme seperti Dewan Pers, Komisi Penyiaran Indonesia, Persatuan Wartawan Indonesia (PWI), Aliansi Jurnalis Independen (AJI) dan organisasi profesi wartawan lainnya, media watch dan perguruan tinggi juga berperan dalam optimalisasi penerapan standar kompetensi wartawan. Caranya dengan mengintensifikan pemantauan dan publikasi kinerja para wartawan berbasis riset valid dan independen secara rutin dan komprehensif. Hasil Monev terkait juga bisa menjadi panduan untuk program pembinaan seperti melalui pelatihan, workshop, seminar, publikasi, mediasi, audiensi dan advokasi. Lembaga-lembaga ini pun dalam bekerja hendaknya profesional, independen, terbebas dari tarikan kepentingan manapun.

Masyarakat pun didorong ikut serta dalam optimalisasi Monev atas penerapan standar kompetensi wartawan. Hal ini mengingat masyarakat adalah khalayak bagi pers. Jika ditemukan penyimpangan, maka masyarakat bisa mengkritisi dan melaporkan masalah ini kepada pihak-pihak terkait, bukan dengan main hakim sendiri. Pelibatan masyarakat dalam Monev terhadap kompetensi wartawan termasuk sebagai bentuk literasi media yakni pemberian pendidikan melek media kepada publik luas.

Tujuannya agar publik bisa berinteraksi secara cerdas dengan pers dalam selektifitas kontenkonten media dan relasi media baik personal, institusi maupun produk-produk pers. atau dalam bahasa David Condiside (1995, dalam Birowo \& Darmastuti, 2014: 369) yakni masyarakat mampu mengakses, menganalisis, mengevaluasi dan mengkomunikasikan informasi dalam berbagai format pesan yang disampaikan oleh media massa baik itu cetak dan maupun elektronik.

\section{Optimalisasi Pemberian Penghargaan (Reward)}

Optimalisasi penerapan standar kompetensi wartawan di Indonesia juga dapat dilakukan melalui optimalisasi penghargaan (reward). Pemberian penghargaan perlu lebih intens dilakukan sehingga menjadi penyemangat bagi kalangan wartawan. Tentu saja pemberian penghargaan dilakukan secara obyektif dan disesuaikan dengan kemampuan finansial perusahaan pers.

Selain dari internal perusahaan pers, optimalisasi penghargaan kepada para wartawan juga bisa melalui berbagai pihak lain baik negeri dan swasta. Penghargaan Pulitzer di level dunia atau Anugerah Adinegoro di pentas Indonesia adalah contoh apresiasi yang sangat baik atas prestasi kerja wartawan yang perlu dilestarikan dan lebih dioptimalkan.

Untuk itu, perlu ditingkatkan penyelenggaraan berbagai ajang kompetisi di bidang jurnalistik baik berita maupun foto dengan ragam kategori dari berbagai pihak. Para wartawan perlu lebih didorong dan difasilitasi agar ikut serta dalam berbagai kompetisi jurnalistik terkait. Dengan demikian kehidupan pers di Indonesia makin sehat dan berkualitas.

\section{Optimalisasi Penerapan Sanksi}

Optimalisasi pemberian sanksi kepada wartawan adalah dalam pengertian sebagai pembinaan atas wartawan yang dinilai melanggar prosedur kerja jurnalisme yang profesional. Untuk itu hendaknya dilakukan secara obyektif, selektif, bertahap, adil, prosedural dan edukatif. Obyektif yakni pemberian sanksi didasarkan atas fakta kasus secara empiris di lapangan, tidak bisa berdasarkan suka atau tidak suka (like or dislike) atau unsur lainnya.

Selektif yakni pemberian sanksi berdasarkan selektifitas kasus (pelanggaran yang dilakukan) secara detil dan komprehensif untuk menghindari kekaburan kasus. Bertahap yakni pemberian sanksi dilakukan secara bertahap seperti pemberian lisan dan teguran tertulis secara bertahap (teguran I, II, III) dan skorsing. Pemutusan hubungan kerja (PHK) adalah pilihan paling akhir ditempuh berdasarkan pertimbangan matang bahwa wartawan terkait benar-benar melakukan kesalahan sangat fatal.

Adil yakni pemberian sanksi memenuhi asas keadilan yaitu menempatkan pemberian sanksi sesuai dengan derajat kesalahan. Dengan demikian terhindar dari tindakan diskriminatif. Prosedural yakni pemberian sanksi didasarkan atas regulasi yang berlaku seperti UU Pers, UU Penyiaran, UU Informasi dan Traksaksi Elektronik (ITE), UU Keterbukaan Informasi Publik (KIP), UU Hak Cipta, Kode Etik Wartawan Indonesia (KEWI), KUHP, UU Ketenagakerjaan. Meski taat asas regulasi, namun semangat pemberian sanksi hendaknya dalam kerangka pembinaan menuju spirit profesionalitas kerja. 


\section{Optimalisasi Kesejahteraan Wartawan}

Sudah menjadi rahasia publik bahwa secara umum kesejahteraan wartawan di Indonesia masih belum sesuai harapan. Aliansi Jurnalis Independen (AJI) Jakarta menyatakan masih banyak perusahaan media yang memberikan upah di bawah layak. Idealnya upah layak jurnalis pemula tahun 2016 sebesar Rp 7,54 juta (www.kompas.com). Namun faktanya, gaji rata-rata reporter di perusahaan media hanya berada di kisaran Rp 3 juta sampai Rp 4 juta rupiah per bulan (www. politik.rmol.co).

Kondisi ini dinilai banyak pihak turut memberikan sumbangsih pada kualitas penerapan standar kompetensi wartawan yakni munculnya perilaku wartawan dan produk jurnalistik yang dinilai tidak profesional. Meski persoalan ini sangat terkait dengan kemampuan finansial perusahaan pers, namun demikian jika tidak ditangani maka kondisi ini dikhawatirkan akan terus berlangsung.

Untuk itu, perusahaan pers dituntut memenuhi ketentuan UU Ketenagakerjaan mengenai standar kesejahteraan karyawan (wartawan). Setidaknya gaji minimal setara upah minimum kota/kabupaten (UMK), pemenuhan berbagai tunjangan dan sebisa mungkin menghindari pemutusan hubungan kerja (PHK). Untuk itu, kemampuan perusahaan pers dalam mengelola bisnis media yang digarapnya menjadi syarat utama tanpa meninggalkan aspek profesionalitas kerja. Atau meminjam istilah Wahyu Utomo (2009: ix), memuarakan dialektika dikotomis antara idealisme wartawan dan praktik institusionalisme pers.

Selain manajemen profesional, kreatifitas bisnis seperti ekspansi bisnis menjadi pilihan strategis untuk menopang dan mendongkrak keuangan perusahaan ditengah kompetisi ketat antarmedia saat ini. Perusahaan pers harus melakukan diversifikasi sumber pendapatan, tidak lagi terbatas pada iklan dan oplah (Kristanto, 2016: 17). Jika income perusahaan pers meningkat, maka kesejahteraan wartawan ikut terdongkrak. Dengan kesejahteraan yang layak, maka diharapkan wartawan akan nyaman dan optimal dalam bekerja.

\section{Optimalisasi Advokasi Wartawan}

Upaya optimalisasi penerapan standar kompetensi wartawan di Indonesia adalah melalui optimalisasi advokasi para wartawan. Reporters without Borders meletakkan Indonesia pada nomor 130 dari 180 negara dalam tingkat kebebasan pers sedunia (www.kompas.com). Lembaga Bantuan Hukum (LBH) Pers mencatat 47 kasus kekerasan terhadap jurnalis selama tahun 2015 (https://m.tempo.co).

Dewan Pers menyebut saat ini ada 8 kasus pembunuhan wartawan yang menjadiganjalan jika menyebut Indonesia sebagai negara dengan pers bebas. Para jurnalis itu antara lain Fuad Muhammad Syafruddin alias Udin, jurnalis Harian Bernas Yogyakarta, yang tewas dianiaya pada 16 Agustus 1996; Naimullah, jurnalis Harian Sinar Pagi, yang ditemukan tewas di Pantai Penimbungan, Kalimantan Barat, pada 25 Juli 1997; Agus Mulyawan, jurnalis Asia Press, yang tewas pada 25 September 1999 di Timor Timur; serta Muhammad Jamaluddin, juru kamera TVRI yang hilang di Aceh pada 2003 (https://m.tempo.co).

Kondisi ini tentu memprihatinkan bagi dunia pers dan iklim demokrasi di Indonesia. Untuk itu perlunya intensifikasi pendampingan bagi wartawan yang berhadapan dengan ancaman kekerasan dan sengketa pers terutama oleh perusahaan pers dan organisasi profesi wartawan. Pendampingan bersifat all out sejak proses awal sengketa hingga akhir sengketa. Pendampingan advokasi dilakukan setelah sebelumnya dilakukan optimalisasi pendampingan mediasi antar pihak yang bersengketa.

\section{Optimalisasi Uji Kompetensi Wartawan}

Upayaoptimalisasipenerapan standarkompetensi wartawan di Indonesia juga dapat ditempuh melalui optimalisasi uji kompetensi wartawan. Kementerian Komunikasi dan Informatika (Kominfo) menyebut hingga Februari 2016 baru sekitar 5.000 wartawan yang sudah melewati uji kompetensi wartawan (UKW) dari sekitar 15.000 wartawan (di Indonesia) (www.teropongsenayan.com).

Untuk itu, uji kompetensi wartawan yang telah berlangsung selama ini perlu terus dijalankan dan pelaksanaannya lebih dioptimalkan baik level wartawan muda, wartawan madya maupun wartawan utama. Optimalisasi uji kompetensi ini untuk semua model ujian baik untuk uji tertulis, praktek, uji jejaring, dokumentasi hasil kerja, studi kasus dan metode lain yang terkait.

Selain itu, optimalisasi juga terkait mekanisme kontrol dari berbagai pihak agar tidak terjadi penyalahgunaan sertifikat kompetensi wartawan. Sependapat dengan Ignatius Haryanto (2014) bahwa sertifikasi wartawan diharapkan untuk menuju perbaikan profesionalitas wartawan di Indonesia, bukan untuk disalahgunakan. 


\section{KESIMPULAN}

Wartawan adalah ujung tombak dalam produksi berita. Jika berita berkualitas, maka pers pun akan berbobot, publik juga akan tercerahkan, kehidupan bangsa pun akan turut tercerdaskan. Untuk itu, standar kompetensi wartawan mutlak diterapkan baik kompetensi kesadaran, kompetensi pengetahuan dan kompetensi skill.

Optimalisasi penerapan standar kompetensi wartawan di Indonesia setidaknya dapat ditempuh melalui: (1) optimalisasi pelatihan/kursus/ workshop/studi banding, (2) optimalisasi monitoring dan evaluasi (Monev), (3) optimalisasi pemberian penghargaan, (4) optimalisasi penerapan sanksi secara secara obyektif, selektif, bertahap, adil, prosedural dan edukatif, (5) optimalisasi kesejahteraan wartawan, (6) optimalisasi advokasi wartawan, (7) optimalisasi uji kompetensi wartawan.

\section{DAFTAR PUSTAKA}

Azra, Azyumardi. (2007). Merawat Kemajemukan Merawat Indonesia. Edisi I. Yogyakarta: Impulse dan Penerbit Kanisius.

Birowo, Mario Antonius dan Rini Darmastuti. (2014). Literasi Media pada Masyarakat Yogyakarta dengan Berbasis Kearifan Lokal Masyarakat Yogyakarta, Proseding, Jakarta: Ikatan Sarjana Komunikasi Indonesia (ISKI).

Dewan Pers. (2005). Kompetensi Wartawan: Pedoman Peningkatan Profesionalisme Wartawan dan Kinerja Pers, Cetakan Ke-2, Jakarta: Dewan Pers didukung Friedrich Ebert Stiftung.

Hikmat Kusumadiningrat dan Purnama Kusumadiningrat. (2003). Jurnalistik Teori \& Praktik, Bandung: Remaja Rosdakarya.

Haryanto, Ignatius. (2014). Apakah Wartawan Perlu Sertifikasi. "Jurnalisme Era Digital: Tantangan Industri Media Abad 21". Edisi I. Jakarta: Penerbit Buku Kompas.

Kristanto, Tri Agung. Ada Asa Perusahaan Pers, Kompas edisi Senin, 29 Agustus 2016.

Maarif, Syafii. (2015). Islam dalam Bingkai Keindonesiaan dan Kemanusiaan: Sebuah Refleksi Sejarah. Jakarta: Mizan.
Pawito. (2005). Komunikasi Politik Media Massa dan Kampanye Pemilihan, Yogyakarta: Jalasutra.

Peraturan Dewan Pers Nomor 1/Peraturan-DP/II/2010 Tentang Standar Kompetensi Wartawan

Utomo, Wahyu. (2009). Menuju Jurnalisme Beretika: Peran Bahasa, Bisnis dan Politik di Era Mondial. Jakarta: Penerbit Buku Kompas.

Severin, Werner J., dan James W Tankard. (2005). Teori Komunikasi Sejarah, Metode dan Terapan di dalam Media Massa. Cetakan Ke-5. Terj. Sugeng Hariyanto. Jakarta: Prenada Media.

Syah, Sirikit. (2011). Rambu-Rambu Jurnalistik: Dari Undang-Undang hingga Hati Nurani. Edisi I. Yogyakarta: Pustaka Pelajar.

Wijaya, Sri Herwindya Baskara. (2015). Jurnalis Profesional: Sebuah Pengantar Konseptual Standar Kompetensi Profesi, Jurnal Komunikasi Massa Volume 8 No 1 Tahun 2015.

Majalah Tempo, 11 April 2016, Indonesia Berutang Delapan Kasus Pembunuhan Jurnalis, https://m. tempo.co/read/news/2016/04/11/063761520/ indonesia-berutang-delapan-kasus-pembunuhanjurnalis, diakses 31 Agustus 2016

Kompas, 6 Juni 2016, Presiden SEAPA: Kekerasan Terhadap Wartawan Indonesia Harus Dihentikan,http://nasional.kompas.com/read/ 2016/05 /06/ 11391101/Presiden.SEAPA.Kekerasan.Terhadap. Wartawan.Indonesia.Harus.Dihentikan, diakses 31 Agustus 2016

Majalah Tempo, 23 Desember 2015, Sepanjang 2015, Terjadi 47 Kekerasan Jurnalis, https://m.tempo.co/ read/news/2015/12/23/173730052/sepanjang-2015terjadi-47-kekerasan-jurnalis, diakses 31 Agustus 2016

Indonesiasatu, 2 Mei 2016, AJI: Gaji Wartawan Pemula Harusnya Rp 7,54 Juta Per Bulan, http:// indonesiasatu.co/detail/aji--gaji-wartawan-pemulaharusnya-rp-7-54-juta-per-bulan

Alfian Risfil, Selasa, 09 Feb 2016, Tahun Ini Menkominfo Minta Semua Wartawan Lakukan Uji Kompetensi, http://www.teropongsenayan.com/30227-tahunini-menkominfo-minta-semua-wartawanlakukan-uji-kompetensi, diakses 31 Agustus 2016 